\title{
Trauma care in South Africa - a call to arms
}

For most of us December 2010 is a fading memory; we will not share the pain felt by 1500 families, grieving another festive season of carnage on South Africa's road system. ${ }^{1}$ From the top strong words have been spoken and promises made, but will anything change? Every month, 1200 deaths occur on our roads, and this shows no sign of decreasing. ${ }^{2}$ If a jumbo jet crashed into OR Tambo's main runway each and every week, how long would we wait before we demanded action? The body count grows, but as we enter the World Health Organization (WHO)'s Decade for Action for Road Safety, ${ }^{3}$ is 2011 the year that we will stand up and do something? What also of the 60000 South Africans who meet their end violently every year? ${ }^{4}$ If simple numbers cannot motivate us, can we be shamed into action by the fact that we have one of the highest rates of traumatic death in the world? ${ }^{5}$ Trauma is at epidemic levels in South Africa, but are we taking this epidemic seriously? Statistics suggest not.

There is no doubt that trauma is an end-product of multiple, complex interactions between education levels, unemployment, poverty, alcohol and drug abuse, poor law enforcement, societal norms and multiple other factors. At a national government level, this complexity and multi-sectoral nature seems to be the obstacle to a strong, co-ordinated response: it is every ministry's responsibility, hence it appears to be no ministry's responsibility. Trauma is the second commonest cause of death in the region, ${ }^{6}$ and for every trauma death, there are countless trauma victims; it is responsible for up to $40 \%$ of hospital emergency centre attendances (millions of cases) each year. ${ }^{5}$ Look a little deeper, and we see that it affects those who potentially have the most to offer to developing societies - the young and healthy. Reducing the overall rate of trauma is critical, but no less important (and a whole lot simpler to achieve) is improving the medical care of victims.

What would this mean for the health services? Trauma care involves multiple health care professionals, multiple medical specialties, and most parts of the hospital in its provision. It encompasses emergency medical care (pre-hospital and emergency centre based); inter- and intra-hospital transfer; definitive surgical and ICU care; and the (much overlooked) rehabilitation services. South Africa has islands of trauma care excellence in a sea of otherwise poorly planned, poorly co-ordinated, poorly resourced services. For example, Metro EMS now report that over $60 \%$ of priority 1 calls are responded to within 15 minutes in Cape Town; in the Eastern Cape, one service responded to only $3.3 \%$ of all calls within one hour. ${ }^{7}$ Existing trauma services are delivered in a postcode lottery: where you live determines your chance of timely, appropriate, high-quality trauma care. This is not a public sector disease; trauma victims fare no better in the private health sector, which (with one or two notable exceptions) also lacks co-ordinated trauma care services.

The only sensible health service response is through the development of an integrated trauma system, the design of which is not complex, but which is long overdue in South Africa. Integrated planning between health managers and (at a minimum) emergency medical services, emergency physicians, trauma surgeons and rehabilitation services is central; trained emergency medicine specialists in emergency centres form a major link in ensuring appropriate and timely care in receiving hospitals; agreed clinical and referral protocols help the right patient get to the right place safely and speedily; and dedicated trauma centres focus trauma surgery and ICU expertise in a co-ordinated regional service. Hardcastle makes a sensible case for the prerequisites before such a system can be in place. ${ }^{8}$ None of these steps are easy; many challenge deeply held positions and mean significant changes from the status quo, and implementing them will cost money. But can we afford to continue to ignore the problem? Three papers in this issue add to the overwhelming body of evidence that we cannot. ${ }^{8-10}$

There are strong national organisations demanding a change. Both the Trauma Society of South Africa and the Emergency Medicine Society of South Africa speak on behalf of the nation's expertise in this area - the time is long overdue for their voices to be heard; the time is long overdue for a South African trauma system; the time is long overdue for trauma to be made a national government priority.

\section{Lee A Wallis}

Division of Emergency Medicine

Stellenbosch University

Tygerberg, W Cape

Corresponding author: L A Wallis (leew@sun.ac.za)

\section{References}

1. http://www.timeslive.co.za/local/article843892.ece/Festive-season-road-death-toll-1551 (accessed 25 January 2011)

. http://www.mg.co.za/article/2011-01-11-minister-decries-festiveseason-road-deaths (accessed 25 January 2011).

World Health Organization. Draft Plan for the Decade of Action for Road Safety 2011-2020. Geneva: WHO, 2010.

4. Matzopoulos R, Seedat M, Cassim M. A profile of fatal injuries in South Africa: Fourth annual report of the National Injury Mortality Surveillance System (NIMSS). South African Medical Research Council,

5. Matzopoulos RG, Prinsloo MR, Bopape JL, et al. Estimating the South African trauma caseload as a basis for injury surveillance. South African Medical Research Council, 1999

6. Trunkey DD. The medical world is too flat. World J Surg 2008;32:1583-1604.

7. Meents E, Boyles T. Emergency medical services - poor response time in the Eastern Cape. S Afr Med J 2010;100:790

8. Hardcastle T. The 11 P's of an Afrocentric trauma system for South Africa - time for action! $S$ Afr Med J 2011:101:160-162 (this issue).

9. Cheddie S, Muckart DJJ, Hardcastle T, Den Hollander D, Cassimjee H, Moodley S. Direct admission versus inter-hospital transfer to a level 1 trauma centre improves survival. S Afr Med J 2011;101:176178 (this issue).

10. Hardcastle T, Steyn E, Boffard K, et al. Guideline for the assessment of trauma centres in South Africa. S Afr Med J 2011;101:189-194 (this issue). 